Article

\title{
Transcriptomic Analysis of Sex-Associated DEGs in Female and Male Flowers of Kiwifruit (Actinidia deliciosa [A. Chev] C. F. Liang \& A. R. Ferguson)
}

\author{
Patricio Zapata ${ }^{1}$ D, Makarena González ${ }^{2}$, Igor Pacheco ${ }^{1,3}{ }^{(D}$, Claudia Jorquera $^{1}$, Claudia Silva-Andrade ${ }^{4}$, \\ Marco Isaac Garrido ${ }^{1}$, Rodrigo Infante ${ }^{1}$ and Juan Alfonso Salazar ${ }^{1,5, * \mathbb{D}}$
}

1 Departamento de Producción Agrícola, Universidad de Chile, Santiago 8820808, Chile; zapata.pzsm@gmail.com (P.Z.); igor.pacheco@inta.uchile.cl (I.P.); cljorquera.s@gmail.com (C.J.); marcogarrido@uchile.cl (M.I.G.); rinfante@uchile.cl (R.I.)

2 Institutos de Ciencias Biológicas, Universidad Santiago de Chile, Santiago 9170124, Chile; makarenagonzalezreyes@gmail.com

3 Instituto Nutrición y Tecnología de los Alimentos, Universidad de Chile, Santiago 7830490, Chile

4 Laboratorio de Biología de Redes, Centro de Genómica y Bioinformática, Universidad Mayor, Santiago 8580000, Chile; silvaandradeclaudia@gmail.com

5 Departamento de Mejora Vegetal, CEBAS-CSIC, Campus Universitario de Espinardo, 30100 Murcia, Spain

* Correspondence: jasalazar@cebas.csic.es

check for updates

Citation: Zapata, P.; González, M.; Pacheco, I.; Jorquera, C.;

Silva-Andrade, C.; Garrido, M.I.;

Infante, R.; Salazar, J.A.

Transcriptomic Analysis of SexAssociated DEGs in Female and Male Flowers of Kiwifruit (Actinidia deliciosa [A. Chev] C. F. Liang \& A. R. Ferguson). Horticulturae 2022, 8, 38. https://doi.org/10.3390/

horticulturae 8010038

Academic Editors: Yuanwen Teng and Zhenhai Han

Received: 9 November 2021

Accepted: 18 December 2021

Published: 30 December 2021

Publisher's Note: MDPI stays neutral with regard to jurisdictional claims in published maps and institutional affiliations.

Copyright: (C) 2021 by the authors. Licensee MDPI, Basel, Switzerland. This article is an open access article distributed under the terms and conditions of the Creative Commons Attribution (CC BY) license (https:// creativecommons.org/licenses/by/ $4.0 /)$.
Abstract: Kiwifruit (Actinidia deliciosa [A. Chev.], C.V. Liang \& A. R. Ferguson, 1984) is a perennial plant, with morphologically hermaphroditic and functionally dioecious flowers. Fruits of this species are berries of great commercial and nutritional importance. Nevertheless, few studies have analyzed the molecular mechanisms involved in sexual differentiation in this species. To determine these mechanisms, we performed RNA-seq in floral tissue at stage 60 on the BBCH scale in cultivar 'Hayward' (H, female) and a seedling from 'Green Light' $\times$ 'Tomuri' $(\mathrm{G} \times \mathrm{T}$, male). From these analyses, we obtained expression profiles of 24,888 $(\mathrm{H})$ and 27,027 $(\mathrm{G} \times \mathrm{T})$ genes, of which 6413 showed differential transcript abundance. Genetic ontology (GO) and KEGG analysis revealed activation of pathways associated with the translation of hormonal signals, plant-pathogen interaction, metabolism of hormones, sugars, and nucleotides. The analysis of the protein-protein interaction network showed that the genes ERL1, AG, AGL8, LFY, WUS, AP2, WRKY, and CO, are crucial elements in the regulation of the hormonal response for the formation and development of anatomical reproductive structures and gametophytes. On the other hand, genes encoding four Putative Sadenosyl-L-methionine-dependent methyltransferases (Achn201401, Achn281971, Achn047771 and Achn231981) were identified, which were up-regulated mainly in the male flowers. Moreover, the expression profiles of 15 selected genes through RT-qPCR were consistent with the results of RNAseq. Finally, this work provides gene expression-based interactions between transcription factors and effector genes from hormonal signaling pathways, development of floral organs, biological and metabolic processes or even epigenetic mechanisms which could be involved in the kiwi sexdetermination. Thus, in order to decode the nature of these interactions, it could be helpful to propose new models of flower development and sex determination in the Actinidia genus.

Keywords: Actinidia; kiwifruit; dioecious plants; RNA-seq; differentially expressed genes; proteinprotein interaction

\section{Introduction}

Kiwifruit is the common name of a berry fruit produced by plants of the Actinidia genus, which belongs to the family Actinidiaceae. This genus contains 76 species originating in China and about 125 taxa known worldwide [1]. However, the kiwifruit species of commercial interest number just over half a dozen. The most important species of 
kiwifruits are the green-fleshed Actinidia deliciosa and the yellow-fleshed Actinidia chinensis. Kiwifruit exhibits a delicious taste and high nutritional value, being a good source of vitamin $C$ and other nutrients such as carotenoids, potassium, magnesium and soluble fibre [2]. In recent decades, kiwifruit has become a crop of great interest, with its production concentrated mainly in six countries: China, New Zealand, Italy, Iran, Greece, and Chile (FAOSTAT, 2021).

The hermaphrodite flower pattern characterizes all Actinidia species. From the functional point of view [3], they correspond to male and female flowers present in different plants (dioecism), usually located at the basal end of the bud. Male flowers carry numerous stamens that produce viable pollen and a rudimentary ovary that lacks styles and does not form ovules [4]. Female flowers contain a well-developed ovary with numerous ovules, and the anthers produce pollen lacking viability [5]. Male flowers seem to have all the genes needed to create the female structure, but the expression of the regulator SyGI, a dominant sex-determination gene, suppresses carpel development [6,7]. This repressive behaviour is not limited to kiwifruits; in asparagus, for example, both sexual organs begin to develop, but later one of them degenerates [8]. Moreover, in the Cucurbitaceae family, cucumber (Cucumis sativus) and honey melon (Cucumis melo) show intraspecific polymorphism in their sex-determination regulating systems. In these species, floral primordia are initially bisexual, then sex determination occurs by the selective developmental arrest of either the stamen or the carpel, resulting in unisexual flowers [9-11].

Current research on kiwifruit focuses primarily on consumer-oriented traits such as fruit flavor [12], aroma [13], appearance [14], and postharvest potential [15,16], but the knowledge of the genetic regulation underlying development and growth, flowering and the determination of sex could be studied more in depth. The elucidation of sex determination mechanisms is relevant for kiwifruit production, due to the dioecious nature of Actinidia and the variation in ploidy level that significantly influences the rate of success in reproduction. Therefore, a better knowledge of these mechanisms will help breeding through the development of precise and efficient tools for reducing the inter-generation time [17].

It is known that Actinidia has an active $\mathrm{Y}$ sex determination system ( $\mathrm{XnX} / \mathrm{XnY})$, where male plants contain the $Y$ chromosome [18,19]. The work of Harvey et al. [20] showed that sex-determining locus is in a sub-telomeric region of chromosome 17, while exhibiting significant recombination rates with markers developed for selection. Thus, the development of molecular markers useful for the screening of female and male plants have been always a great challenge in any kiwi breeding program. Early studies identified two RAPD markers linked to the sex differentiation in Actinidia chinensis, to use them for screening in populations. Then, SCAR primers were designed due to their linkage with the male determining ' $Y$ ' locus. Although, however, these primers were useful to distinguish between female and male plants of A. chinensis and even in A. deliciosa species with related polyploidy, they were not useful for more distantly related species of Actinidia. For this reason, the most genetically isolated kiwi species with different ploidy increase the complexity of the kiwi genome. They may also make it more difficult to design sexdetermination molecular markers, while lacking the polymorphism linked to the kiwi sex determination [17].

Fraser et al. [18] created genetic maps for fine mapping of sex-determination locus in A. chinensis and, more recently, Scaglione et al. [19] mapped a locus controlling the sex determination in chromosome 25. Other authors have identified markers for assisted selection in kiwifruit seedlings [21]. Li et al. [22] identified 27 differentially expressed genes (DEGs) that participate in the sex determination in A. arguta, among them WUSCHEL, CONSTANS, LFY/FLO. Tang et al. [23] performed a comparative transcriptome analysis of female and male flowers of kiwi, providing gene expression and functional genomics studies in A. chinensis.

Although Akagi et al. [6] identified a regulator of the type $C$ cytokinin response as a possible sex-determining gene in Actinidia, and Akagi et al. [7] later identified a 
second Y-encoded sex-determiner that we named Friendly Boy (FrBy), which exhibits strong expression in tapetal cells, few studies have focused in unveiling the transcriptional interactions and modelling molecular mechanisms underlying the sex-determination in A. deliciosa. The availability of affordable approaches for transcriptome profiling based on Next Generation Sequencing technologies (NGS) allows not only the determination of the expression of a gene but also characterization ofthe transcriptomic regulation networks underlying multiple biological phenomena, including the development of sex-specific organs in plants.

The objective of this study is to perform an analysis of comparative transcriptomics in the sex differentiation of $A$. deliciosa, through transcriptome sequencing of libraries of male flowers of $A$. deliciosa cv. 'Green Light' $\times$ 'Tomuri' and female flowers of $A$. deliciosa cv. 'Hayward'. Highly commercialized varieties in Chile benefit from the floral coincidence of both varieties, where 'Green Light' $\times$ 'Tomuri' blooms in advance of 'Hayward', successfully pollinating it [24]. This analysis will allow us to (i) identify differentially expressed genes related to the sex determinism of kiwifruit plants, and (ii) propose transcriptional regulation networks participating in this process.

\section{Materials and Methods}

\subsection{Plant Material and RNA Extraction}

Vines of kiwifruits were grown at the Experimental Station of the University of Chile, located in Rinconada de Maipú in Santiago de Chile. Flowers from female 'Hayward' $(\mathrm{H})$ and male 'Green Light' $\times$ 'Tomuri' $(\mathrm{G} \times \mathrm{T})$ seedlings were collected just after the flowers started anthesis (corolla bell-shaped, 60) and previous to full flowering (65) according to the Salinero phenological BBCH scale [25]. The male seedling was obtained by crossing of 'Green Light' $\times$ 'Tomuri' in 2010 (Curicó, VII region of Chile) as a result of the FONDEF project of the Chile government (D09I1136) (Figure 1). According to Caporali et al. [26] the key of developmental stage for sex differentiation is when the flowers reach between 3.5-4.5 mm (stage 3, pistil: female with ovule primordium and male no ovule primordium). However, Caporali et al. [26] further consider pollen degeneration in female flowers when they reached 6-7 mm (stage 6, pistil: macrogametogenesis in female and no ovule primordia in male flowers). Therefore, we decided to collect flower tissues closer to stage 6 [26]. The whole flower tissues were frozen in liquid nitrogen and stored at $-80{ }^{\circ} \mathrm{C}$. The samples were composed of a pool of male $(\mathrm{G} \times \mathrm{T})$ and female $(\mathrm{H})$ flowers from three random trees, considering for RNA extraction one and three biological replicates for male and female flowers, respectively. Plant Total RNA extraction kit (Spectrum ${ }^{\mathrm{TM}}$ ) was used for RNA extractions, according to the manufacturer's instructions.

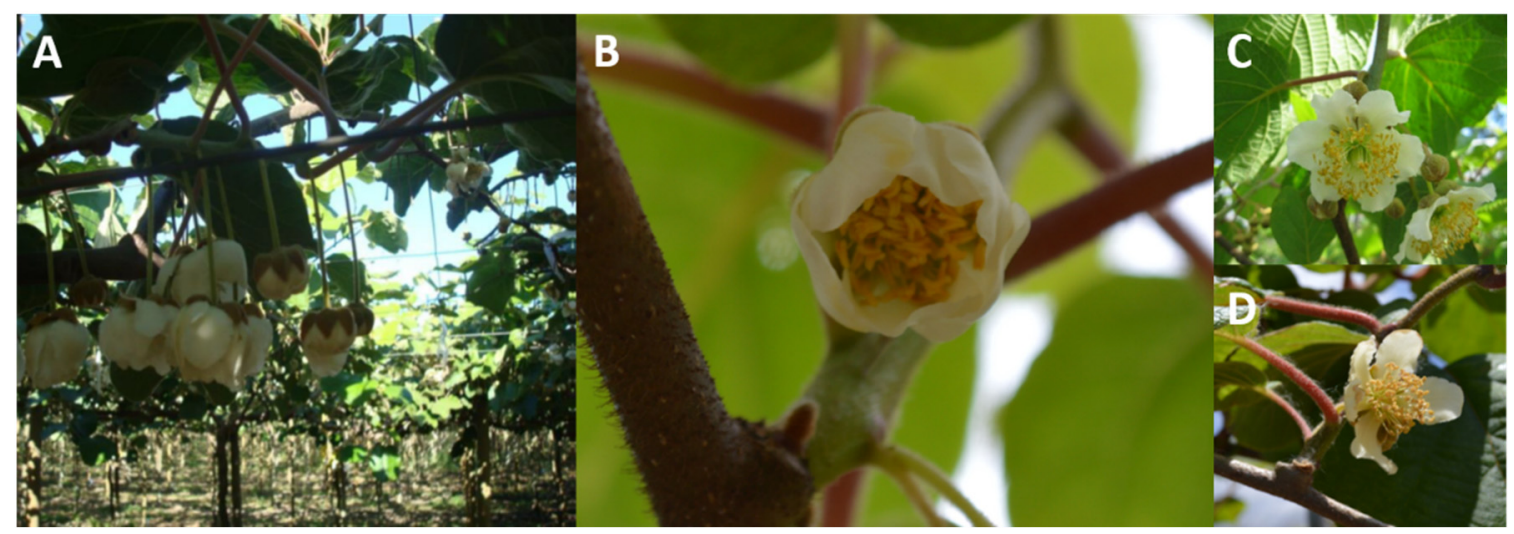

Figure 1. (A) Experimental orchard where the crossings took place (Curicó, VII region of Chile). (B) Phenological state of female and male flowers with corolla bell-shaped (60). (C,D) Detail of 'Hayward' female flower (C) and ' $G \times T^{\prime}$ male flower (D) in full flowering (65). 


\subsection{Sequencing, Assembly and Gene Expression}

Total RNA was used to prepare cDNA libraries using the Illumina Dynabeads ${ }^{\circledR} \mathrm{mRNA}$ DIRECT ${ }^{\mathrm{TM}}$ Kit. The RNA integrity was evaluated by Fragment Analyzer Automated CE System (AATI) and quantified using the Qubit ${ }^{\circledR}$ RNA BR Assay kit. For library construction, we used one microgram of RNA sample as input for Illumina ${ }^{\circledR}$ TruSeq RNA HT Sample prep kit, according to the manufacturer's instructions. The final libraries were analysed on an NGS kit for Fragment Analyzer, and quantified by Qubit 2.0, using Qubit ${ }^{\circledR}$ DNA BR Assay kit. Libraries were sequenced on the HiSeq 2500 platform (Illumina Inc., San Diego, CA, USA). All the raw reads in the FastQ format, including the pair-end and replicates, are available in the NCBI Short Read Archive (SRA) database under the bioproject numbers PRJNA750600 (SAMN20474758) and PRJNA564374 (SAMN12717695, SAMN12717694 and SAMN12717693) for male flowers $(\mathrm{G} \times \mathrm{T})$ and female flowers $(\mathrm{H})$ respectively. Sequence alignment was performed with Bowtie v2 software [27], using 'Hongyang' (Actinidia chinensis) as the reference genome (National Center for Biotechnology Information, NCBI). Samtools4 v0.1.19 [28] was used to convert the files in alignment/sequence map (SAM) format into binary alignment map (BAM) format. The SAM format is a generic format used to store nucleotide sequence alignments, while BAM is the compressed version of the SAM format. The abundance of transcripts and the transcriptome assembly of each sample were created using Cufflinks v.2.2.1.3 [29], using the BAM files resulting from the alignment. Assembled transcriptomes, annotated genome, and Actinidia chinensis (NCBI) genome sequence were merged into a single gtf format using the Cuffmerge tool. The Cuffdiff by differential gene expression analysis and the results obtained were uploaded with the CummeRbund6 visualization package to manage, visualize and integrate all the data produced by the Cuffdiff analysis, using the R7 statistical information environment (version 3.3.3). For the analysis of the differentially expressed genes between samples, DEseq2 package v2.11.40.2 was used [30]. FPKM (Fragments Per Kilobase of transcript per Millon mapped reads) was used to measure the transcript abundance of each gene; those with a fold-change of $\geq 2$ and a false discovery rate (FDR) $<0.05$ were considered significant DEGs [31].

\subsection{Gene Ontology and Network Analysis}

The general gene enrichment of GO terms for biological processes was made using BiNGO tool (Biological Networks Gene Ontology), implemented for Cytoscape version 3.8.0 [32,33], which calculates over-represented GO terms in the network and displays them as a network of significant GO terms. ClueGO [34,35] plugin of Cytoscape was used for enrichment analysis of DEGs [36,37]. GO classifies functions along with three aspects, including molecular function, biological process, and cellular component. Pathway enrichment analysis can identify the most critical metabolic and signal transduction pathways in which differentially expressed genes are involved. Kyoto Encyclopedia of Genes and Genomes $[38,39]$ is a public database of metabolic and regulatory pathways, and a powerful instrument for the analysis of metabolism and metabolic networks. We determined the functional classes for which obtained DEGs showed significant enrichment in GO terms and pathways, based on a hypergeometric distribution. Benjamini-Hochberg method was used to correct the determined $p$-value. A corrected $p$-value $\leq 0.05$ was considered to represent a significant enrichment of genes.

With the information from the DEGs and the STRING database [40], a protein-protein interaction (PPI) network was built which was complemented with prominent genes from various articles such as putative sex-associated genes in male and female flowers in the Genus Actinidia, such as PME3 and ARFA1F [41]; AGL8, AGL9 and PI [42]; RRF, TAF15, TSF, HRGP5, LFY and STIP [43]; PAO1, SAUR32, SAUR51, SAUR50, BEH1, BHLH013 and RGL1 [23]; RR24, FT and FLAsx [6,7]. We consider a score $>0.6$ for DEGs, taking $A$. thaliana as the comparative model in interactions. The Cytoscape platform was used to visualize the PPI interaction network for DEGs and to identify the essential genes of the regulatory pathway [36]. 


\subsection{RT-qPCR Validation}

The oligonucleotide primers were designed from genes potentially involved in sex determination, using the software Primer3 version 0.4.0 [44]. The selected housekeeping reference gene was GLUCOSE-6-PHOSPHATE ISOMERASE (PGI, Achn221981), a dimeric enzyme that catalyses the conversion of glucose-6-phosphate to fructose-6-phosphate. The selection of the reference gene was made from the internal data of RNA Seq, following the criteria set forth by Zhou et al. [45]. RT-qPCR was carried out using KAPA SYBR ${ }^{\circledR}$ FATS Universal qPCR Kit (Kapa Biosystems, Bunkyō, Tokyo) on Eco Real-Time PCR System (Illumina). Each reaction mixture contained $1.0 \mu \mathrm{L}$ of cDNA, KAPA SYBR ${ }^{\circledR}$ FATS Universal qPCR Kit $5 \mu \mathrm{L}$, KAPA SYBR ${ }^{\circledR}$ ROX Low (50X) $0.2 \mu \mathrm{L}$, PCR direct primer $\left(10 \mu \mathrm{mol} \cdot \mathrm{L}^{-1}\right)$ $0.2 \mu \mathrm{L} \mathrm{PCR}$, reverse primer $\left(10 \mu \mathrm{mol} \cdot \mathrm{L}^{-1}\right) 0.2 \mu \mathrm{L}, 3.4 \mu \mathrm{L}$ ddH2O, to a final volume of $10 \mu \mathrm{L}$. The PCR conditions were $95^{\circ} \mathrm{C}$ for $3 \mathrm{~min}$, followed by 40 cycles of $95^{\circ} \mathrm{C}$ for $3 \mathrm{~s}$, $60{ }^{\circ} \mathrm{C}$ for $30 \mathrm{~s}$, and $72{ }^{\circ} \mathrm{C}$ for $35 \mathrm{~s}$. The quantification of relative gene expression levels was carried out using the Pfaffl method, based on the expression levels of target gene vs. a housekeeping gene [46] and cDNA from three replicates of total RNA per genotype being each sample amplified in duplicate.

\section{Results}

\subsection{General Data of the RNA-seq}

The results obtained through RNAseq yielded 83,429,978 and 91,667,860 raw reads from 'Hayward' $\left(\mathrm{H}\right.$ \%) and 'Green Light' $\times$ 'Tomuri' $\left(\mathrm{G} \times \mathrm{T} \sigma^{7}\right)$ libraries, respectively. After eliminating the low-quality reads, the adapter sequences and the rRNA readings, we obtained 73,001,231 and 80,209,378 clean reads for $H$ and $G \times T$, respectively (Table 1). The overall read mapping rate reached $57.20 \%$ for 'Green Light' $\times$ 'Tomuri' while for 'Hayward' it reached 48.5\%. All clean reads are available in the NCBI Short Read Archive (SRA). Finally, we identified 24,888 $(\mathrm{H})$ and 27,027 $(\mathrm{G} \times \mathrm{T})$ genes, of which 6413 were DEGs (Table S1). In a similar study of comparative transcriptomes of young floral buds between female 'Hongyang' and a male from a F1 between 'Hongyang' (ㅇ) and 'Guihai No. 4' ( $\left.0^{\top}\right)$, a close percentage of mapped reads was obtained; however, the number of mapped reads (16-25 million) was lower than in the current study (35-45 million). In addition, the GC content was similar for both sequencing (40-45\%) [23].

Table 1. Summary of sequence analysis and mapping.

\begin{tabular}{ccccc}
\hline & \multicolumn{2}{c}{ G $\times$ T } & \multicolumn{2}{c}{ H } \\
\hline Alignment Statistics & Counts & $\begin{array}{c}\% \text { of Total } \\
\text { Reads }\end{array}$ & Counts & $\begin{array}{c}\% \text { of Total } \\
\text { Reads }\end{array}$ \\
\hline Reads Input & $80,209,378$ & - & $73,001,231$ & - \\
Reads mapped left & $46,514,175$ & $57.99 \%$ & $36,135,609$ & $49.50 \%$ \\
Multiple alignments left & $3,114,693$ & $6.70 \%$ & $4,088,069$ & $5.60 \%$ \\
Reads mapped right & $45,190,039$ & $56.34 \%$ & $34,602,583$ & $47.40 \%$ \\
Multiple alignments right & $3,009,555$ & $6.66 \%$ & $4,088,069$ & $5.60 \%$ \\
Overall read mapping rate & $45,852,107$ & $57.20 \%$ & $35,405,597$ & $48.50 \%$ \\
Aligned pairs & $36,321,861$ & $45.28 \%$ & $29,930,505$ & $41.00 \%$ \\
Multiple alignments & $2,438,520$ & $6.71 \%$ & $1,646,178$ & $5.50 \%$ \\
Discordant alignments & 206,108 & $0.57 \%$ & 119,722 & $0.40 \%$ \\
Q20(\%) & & $97.87 \%$ & & $97.32 \%$ \\
Q30(\%) & & $94.59 \%$ & & $95.30 \%$ \\
GC(\%) & & $46.68 \%$ & & $45.74 \%$ \\
\hline
\end{tabular}

\subsection{DEGs Function Annotation}

GO results showed that 922 terms $(87.3 \%)$ were significantly enriched in the biological process category, specifically genes associated with the cellular process $(45.1 \%)$, metabolic process $(38.7 \%)$, biosynthetic process $(15.9 \%)$, and response to stress $(15.5 \%) .975$ GO terms $(92.3 \%)$ were enriched in the molecular function category, excelling genes related to binding $(42.0 \%)$, catalytic activity $(48.5 \%)$, transferase activity $(17.6 \%)$ and nucleic acid 
binding (16.8\%). 849 GO terms (80.4\%) were in the cellular component category, including extracellular (69.2\%), intracellular (46.0\%) and cytoplasm (31.9\%). The GO terms (Figure 2 ) associated with DEGs are closely related to cell division and differentiation, signaling, transport, cellular, enzymatic, and metabolic processes (Table S2).
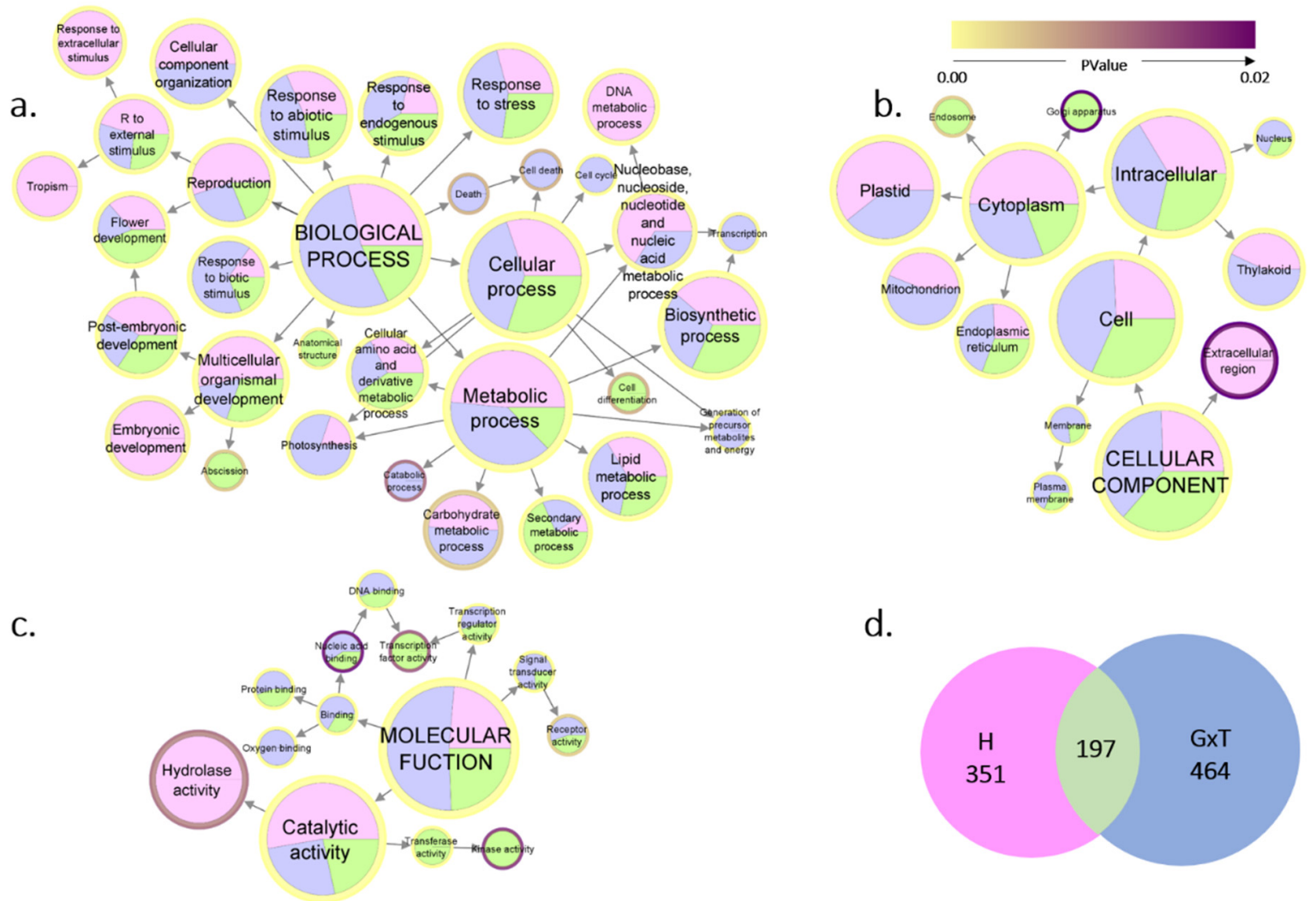

d.

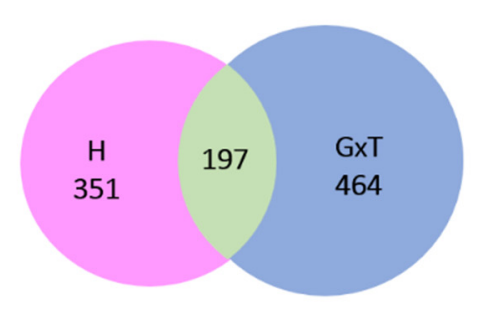

Figure 2. Functional enrichment analysis performed for all DEGs in flowers with the BINGO plugin in Cytoscape. Assigned GO terms were used to classify functions of DEGs based on (a) biological processes, (b) molecular functions, and (c) cellular components. Circle size represents GO hierarchy; the larger area of the circle, the higher hierarchy of the GO-term. The border colour of nodes represents the $p$-value, as shown by the legend on the graph; the deeper the shade the more significant the enrichment level. The threshold of hypergeometric distribution of the functional annotation was set at $p<0.05$ and FDR $<0.05$. (d) Venn diagram showing the number of differentially expressed genes between female 'Hayward' $(\mathrm{H})$ and male 'Green Light' $\times$ 'Tomuri' $(\mathrm{G} \times \mathrm{T})$ female flowers.

Additionally, assignments of KEGG were used to classify the functional annotations of the identified DEGs on each metabolic pathway, to better understand the biological functions and enrich the biological path of each DEG-derived transcript. The results show that DEGs are present in 20 main biological pathways, including the pathways of transduction of plant hormone signals, plant-pathogen interaction, metabolism of amino and nucleotide sugars, interconversions of pentose and glucuronate, metabolism of glutathione, metabolism of galactose, and the MAPK (Mitogen-Activated Protein Kinase) pathways, that play a critical role in processes such as hormonal and developmental signaling (Figure 3 and Table S3). On the other hand, apart from the metabolic pathways mentioned, several genes encoding methyltransferase enzymes were up-regulated mainly in the male flowers, which could be proof that epigenetic mechanisms through DNA methylation would be involved in the kiwi sex-determination (Table S1). 


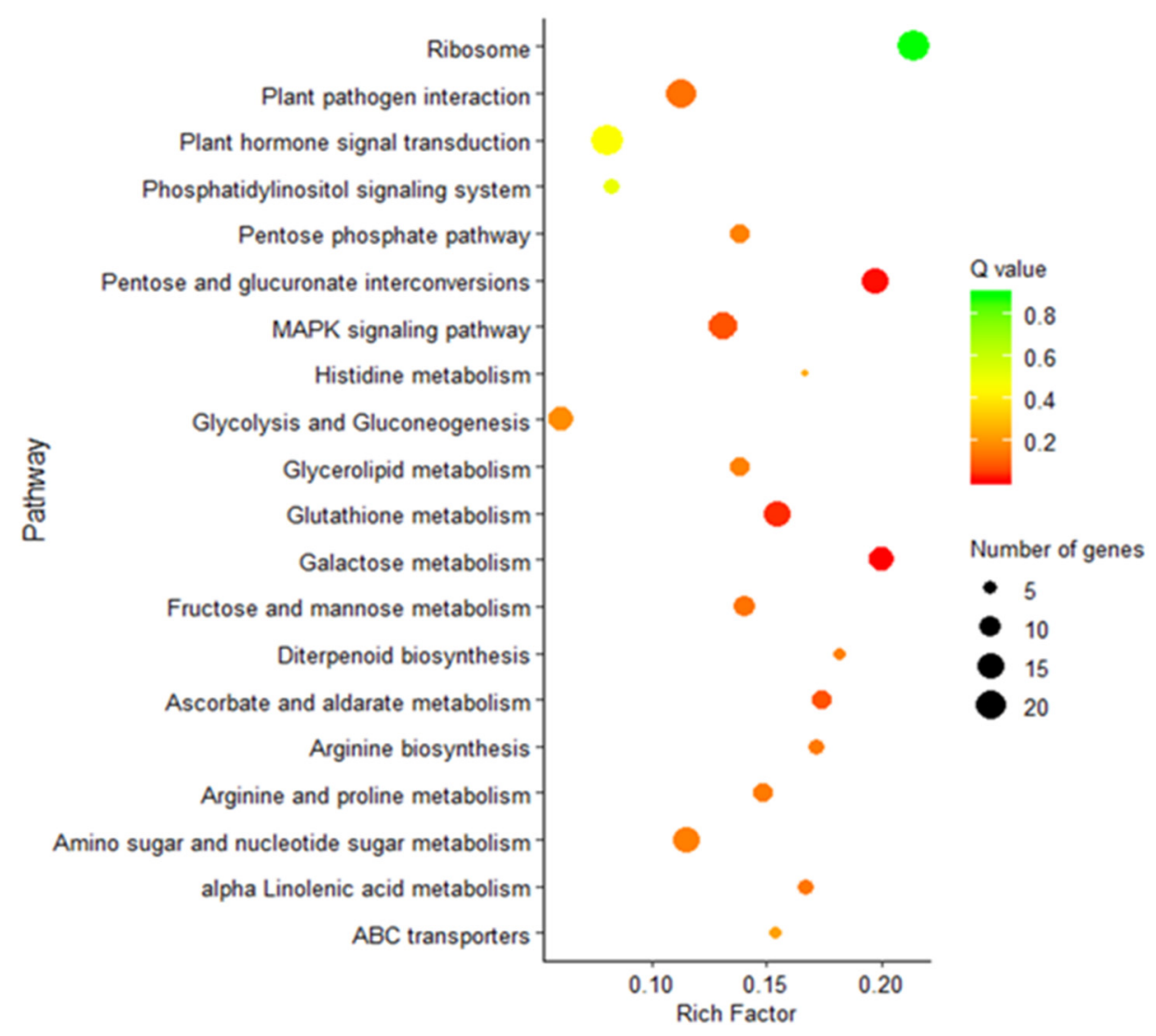

Figure 3. KEGG pathway analysis of DEGs. Advanced bubble chart shows enrichment of DEGs in signaling pathways. Y-axis label represents pathways, and the $\mathrm{X}$-axis label represents the rich factor. Size of the bubble represents the amount of DEGs enriched, and the colour shows the enrichment means in pathways.

In addition, to establish the functional relationship of differentially expressed genes and the possible regulation between them, the data was imported into the STRING tool, identifying genes associated with regulation and hormonal responses, as well as the formation and development of reproductive structures such as gynoecium (ovule) and androecium (stamen). Only PPI with a score greater than 0.6 were extracted (Table S4). In Figure 4, transcription factors (TF) such as AGAMOUS (AG), AGAMOUS-LIKE 8 (AGL8), LEAFY (LFY), WUSCHEL (WUS) and CONSTANS (CO) that promote transcription of another TF called Flowering Locus T (FT) were shown. These transcription factors present a high degree of interaction and centrality between the units obtained, since they act in a combinatorial manner, promoting the identity of the floral meristem. APETALA2 (AP2), involved in plant ovule development, and $L F Y$, linked to hormone response, are both interconnected and implicated in the flower development. Furthermore, we identified genes that regulate different hormonal responses such as ethylene biosynthesis (ACS6), ethylene response genes (EIN2 and EI305), and genes involved in the signaling of gibberellic acid (SLY1). AP2 interacts with the ethylene response genes and is involved in the specification of floral organ and meristem identity as well as ovule development. In addition, $A P 2$ interacts with WUS which is implied in anther development and pollen germination. Finally, we also locate the sex determinant gene $S y G l(R R 24)$ identified by Akagi et al. [6] in the PPI network (Figure 4); however, no gene expression was found in our female and male flower tissues. The most detailed expression of coding genes from the PPI is shown in a heatmap (Figure S1). 


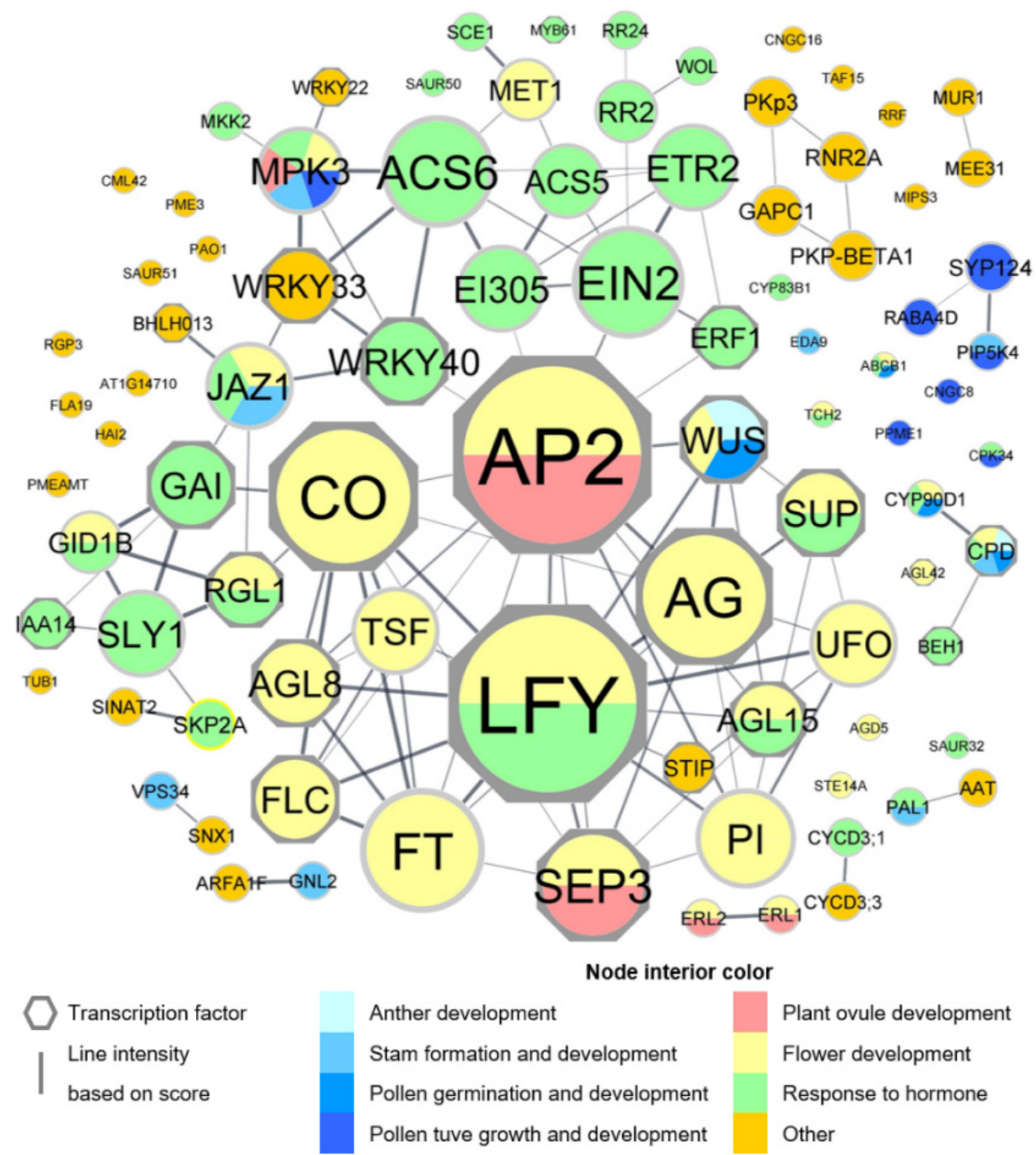

Figure 4. Protein-protein interaction (PPI) network of differentially expressed genes of the 'Green Light' $\times$ 'Tomuri' $\left(\mathrm{G} \times \mathrm{T} \sigma^{7}\right)$ and Hayward $(\mathrm{H}$ q). The node represents the protein, the size of the node is proportional to the number of proteins that interact. the interaction with score $>0.6$ were chosen for analysis.

\section{3. $R T-q P C R$ Validation}

A total of 15 DEGs identified through transcriptomic analysis were validated by RTPCR, using RNA as a template to synthesize complementary DNA (cDNA), isolated from male and female flowers. The genes selected for validation include mainly those involved in sexual reproduction in plants. The primers of the candidate genes are shown in Table S5. The reported genes (Figure 5) showed a higher expression in $G \times T$ with the exception of Achn018291 (MYB), which is related to plant hormones and development of floral organs, Achn182651 (AG) and Ach19261 (ERF), related in plants of Cucumis genus to positive transcription to regulate the determination of sex [47]. 

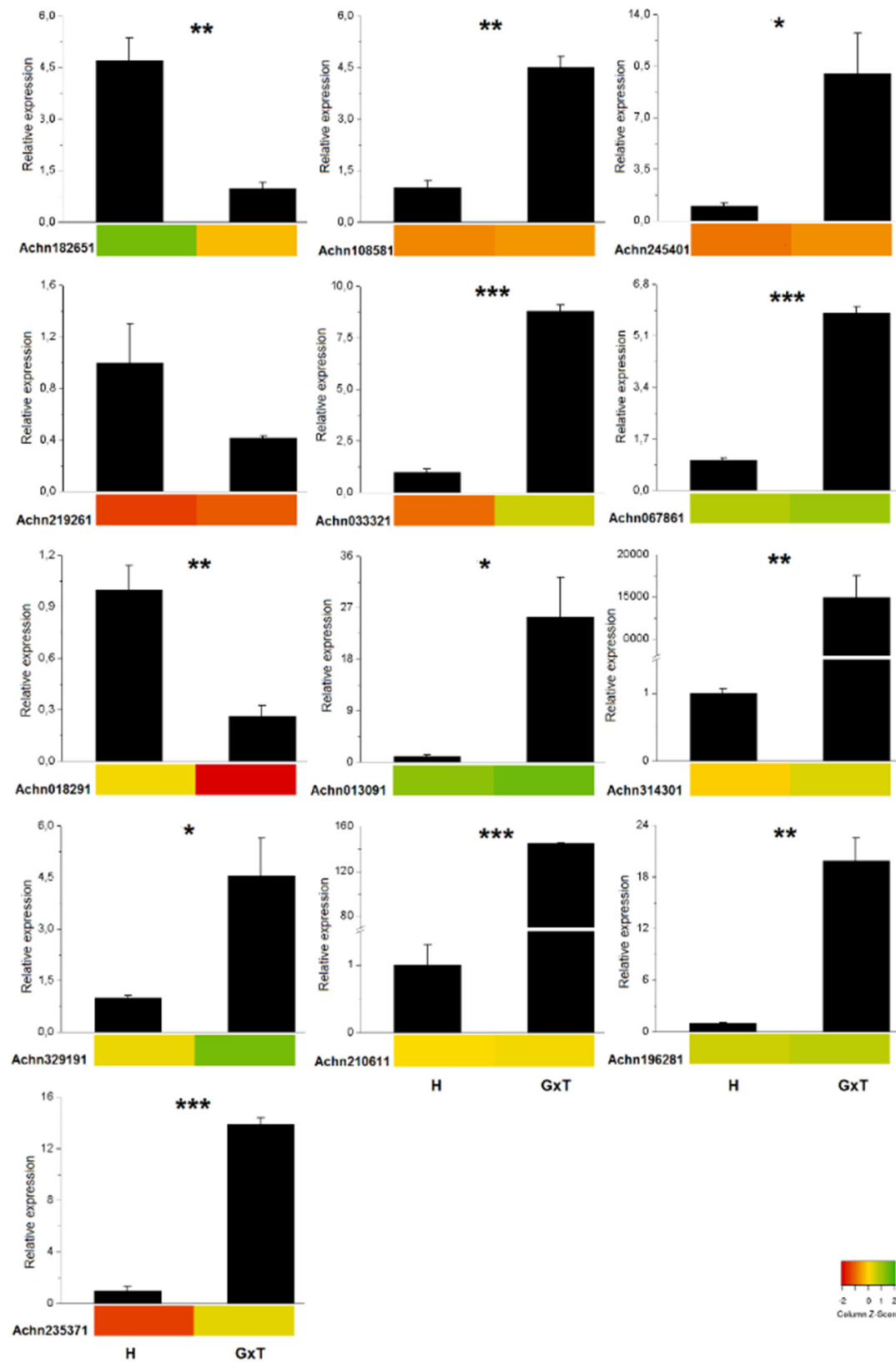

GXT

Figure 5. The expression levels of genes revealed by RT-qPCR and RNA-seq. The heatmap shows the FPKM values for the 15 selected candidate genes. The color scale indicates changes in the fold of gene expression. The bar graphs show the results of RT-qPCR in terms of relative expression. On each panel, left bars represent $\mathrm{H}$-female samples, and right bars represent $\mathrm{G} \times \mathrm{T}$-male samples. The annotation of the selected genes was: Achn182651: AGAMOUS MADS-box transcription factor; Achn108581: Transcription factor, contains DNA-binding, integrase-type domain; Achn245401: CONSTANS protein; Achn219261: Ethylene-responsive transcription factor; Achn033321: Ethylene-responsive transcription factor; Achn067861: Ethylene receptor 2; Achn018291: Putative MYB transcription factor; Achn013091: Ubiquitin-conjugating enzyme; Achn314301: WRKY transcription factor 1; Achn329191: WRKY transcription factor; Achn210611: homeobox-leucine zipper protein; Achn196281: MADS-box transcription factor; Achn235371: MADS-box transcription factor. Achn221981 (PGI) was used as the reference gene. The error bars in each column indicate SD of two replicates. The different asterisks on the bars indicate statistically significant differences with a $p<0.10={ }^{*}, p<0.05={ }^{* *}$ and $p<0.01=* * *$ (one-way ANOVA, Tukey tests). 


\section{Discussion}

\subsection{TFs Differentially Expressed in Male and Female Flowers}

Differentially expressed transcription factors (TFs) control the expression of effector genes and therefore, in our model of study, they could regulate the expression of genes leading to determination of the identity of the floral organs. Based on the analysis of the different TFs groups, we identified in each library, groups of sex-specific DEGs, presumably associated with the identity of the floral organ. Flower formation occurs through a series of sequential steps. First, the activity of floral meristem identity genes (e.g., APETALA, LEAFY, CONSTANS and TERMINAL FLOWER) determines floral meristem development. Second, the floral meristem is patterned into the whorls of organ primordia through the activity of floral-organ identity genes [48-50].

In Arabidopsis, the antagonistic action of two floral homeotic genes, APETALA2 (AP2) and AGAMOUS (AG) defines identity of perianth and reproductive organs [51]. AP2 genes play a central role in the specification of floral identity, particularly for a regular development of sepals and flower petals [52]. $A G$ genes are required for the correct development of stamens and carpels, playing a role in maintaining the determination of the floral meristem [53]. In other species such as tomato, to determine the participation of the AG genes, a silencing of RNAi (RNA interference) was carried out, where transgenic tomato lines were produced that specifically regulate the accumulation of TAGL1 (TOMATO AGAMOUS-LIKE1) or TAG1 transcripts (AGAMOUS TOMATO). The TAGL1 RNAi lines showed no defects in the identity of the stamen or carpel. In contrast, TAG1AR-Ni lines showed defects in stamen and carpel development [54].

In the present study, the DEGs related to AP2 were identified, according to the categories classified in this family, with a higher expression in female (H) (Achn013111, Achn167071, Achn344321) or in male flowers ( $\mathrm{G} \times \mathrm{T})$ (Achn108581, Achn277471, Achn170441) (Figure S1). Varkonyi-Gasic et al. [42], identified a kiwi gene with high levels of homology with AP2 and AP2-like genes from other plant species. Transcription was abundant in the kiwi flower, particularly in the petal, suggesting a role in the identity of the floral organ. In contrast, the DEGs that belong to transcription factors of the $A G$ family (Achn182651) are up-regulated in $\mathrm{H}$, which indicates that these proteins may play an essential role in the regulation of sex in A. delicious. Moreover, the biological relationship in STRING (Figure 4), showed an antagonistic relationship between these two families, coinciding with the phenomenon that occurs in A. thaliana [55], and validating our analysis by reporting gene expression with contrasting effects on flower development. Regarding the results of the relative expression of these genes, a higher expression of $A P 2$ was quantified in male flowers $(\mathrm{G} \times \mathrm{T})$ while $A G$ was up-regulated in female flowers $(\mathrm{H})$. These results agree with the trend observed by the FPKM values, and could indicate and support the antagonistic relationship seen of these two genes in A. thaliana (Kiwifruit floral gene APETALA2 is alternatively spliced and accumulates in aberrant indeterminate flowers in the absence of miR172, [55]).

The TF Asymmetric leaves 1 (AS1; Achn109411) encodes for a Myb domain-containing protein that is involved in cell differentiation in leaves, promotes cell differentiation, regulates gibberellins [56], and acts positively on the flowering process, linked to the Flowering Locus T $(F T)$ promoter and allowing the expression of $F T$ forming a functional complex with CONSTANS (CO; Achn245401) [57]. CO genes in A. thaliana promote flowering and encode a protein that shows similarities with zinc finger transcription factors [55]. Transgenic plants that contain additional copies of $\mathrm{CO}$ start blooming process before the wild type, which suggests that $C O$ activity limits the flowering time [55]. In the DEG library, one gene was found under the $C O$ annotation (Achn245401), whose level of gene expression is higher in male flowers, which interacts with transcription factors such as AP2, FLC, AGL8, RGL1, $A G$ and Protein FT (Figure 4). In other works $[58,59]$ it was considered a network center, capable of integrating external and internal signals in the flowering pathway photoperiod, where CO activates TWIN SISTER OF FT (TSF) and FT [59-61]. In turn, TSF and FT encode a long-range signal (florigen) that carries information about the induction of leaf flowering to the shoot apical meristem $(S A M)[59,61]$. 
The WRKY family of proteins are an important TF superfamily that is involved in essential functions in various responses to stress [62,63], developmental processes [64], physiological processes $[62,63,65]$, or associated with $M A P K$ proteins which are involved in the development and function of pollen in Arabidopsis [66]. For example, 35S: WRKY33 transgenic plants flower slightly earlier than wild type [67]. Transcriptional analysis identified genes belonging to the WRKY family (WRKY 22, WRKY 33 and WRKY 40), showing higher expression in male flowers, suggesting that they could be a crucial part of pollen development.

The AGL family of regulatory factors is involved in flower determination and confers the identity of the reproductive floral organs, included stamens and carpels. In $A$. thaliana, AGL24 is responsible for the identity of the floral organ [68]. Furthermore, considering the ABCDE model for flower development, it was shown that AGL24 together with ap1 and SVP act redundantly to suppress the expression of class B (stamens and petals), C (stamen, carpels and ovaries) and E (all floral whorls) genes [68-70], being E-class, floral homeotic genes expressed in each whorl of the floral organs. Within the PPI analysis, we observed representatives of the $A G L$ family such as $A G L 8$, which promotes the early identity of the floral meristem in synergy with APETALA1 [71], or AGL15 involved in the negative regulation of flowering, probably through the photoperiod pathway. AGL15 acts as an activator and a repressor of transcription [72-74], while AGL42 acts in the control of the flowering time, promotes the flowering in the bud of apical and axillary meristems, acts through a gibberellin-dependent pathway [70], and plays a role in controlling senescence and abscission of flower organs by repressing ethylene responses [75].

\subsection{Methyltransferase Enzymes Expressed in Male and Female Flowers}

DNA methylation is a major epigenetic modification that regulates gene expression and therefore participates in transitions between stages of floral development. To explore whether DNA methylation plays different roles in the floral development of male and female dioecious plants, several studies have been conducted in different species. Cheng et al. [76] applied 5-azacitidine (5-azaC) (DNA methylation inhibitor) in trunks of female and male Salix viminalis L. before the initiation of the floral buds. 5-azaC increased the number, length, and diameter of flower buds in female trees, but decreased these parameters in males. In contrast, studies in Arabidopsis revealed that extensive de novo methylation and demethylation occur during flower development [77]. Other studies point out that the loss of methylated cytosine in the promoter FLOWERING WAGENINGEN (FWA) activates the expression of the associated gene, resulting in the late-flowering phenotype [78]. In addition, in Arabidopsis, have been identified pathways indicating that DNA methyltransferase 1 (MET1), as well as chromylmethylase 3 (CMT3), can maintain the methylation states of GC and CHG, while chromylmethylase 2 (CMT2) maintains $\mathrm{CHH}$ methylation level [79].

As for kiwifruit, it was found that the expression of DNA methylases is more prominent in stems and flowers, while DNA demethylases are more expressed in flowers, stems and young leaves [80]. Other studies have focused on methylesterase pectins (PME) mediators of demethylsesterification of peptic polysaccharides such as homogalacturonano, the main component of the cell wall of the primary plant in the apoplasm. SMEs are involved in a number of development processes, including pollen development and pollen tube growth, through fine-tuning the methyl esterification status of pectin. Kim et al. [81], to determine the importance of PME in kiwi, isolated a full-length cDNA (KiwiPME1) encoding PME from kiwis and characterizing its molecular characteristics. Expression of KiwiPME1 was largely detected in kiwi pollen grains, but not in the vegetative tissues investigated. Analysis of the expression pattern of KiwiPME1 between different floral tissues of male and female plants revealed that KiwiPME1 was specifically expressed in the flower bud stamens on male and female plants, while its expression was detected only in the stamens of male plants when the flowers opened. 
Expression analysis of the KiwiPME1 promoter fused with the GUS indicator gene in Arabidopsis showed a pattern very similar to kiwi. The study suggests that KiwiPME1 located in the cell wall is probably involved in the development of pollen and the growth of the pollen tube of dioecious species such as kiwi [81]. In other related studies, Wormit and Usadel [82] using the antisense expression of a pollen-specific PMEI of broccoli (Brassica oleracea) in Arabidopsis, achieved the silencing of the orthologue gene of Arabidopsis AT1G10770, which resulted in male sterility. This suggests that the alteration of PME activity unbalances pectin distribution and affects cell wall dynamics in the pollen cell wall, with a detrimental effect on fertility [83]. The appearance of this mechanism suggests a role of PME inhibitors during pollen development and reproductive processes [82].

In the present work, four Putative S-adenosyl-L-methionine-dependent methyltransferases, classified as methyltransferase pectins were up-regulated in male (Achn201401, Achn281971 and Achn047771) and female flowers (Achn231981) (Figure S2 and Table S1), which may be likely to be involved in the development and growth of the pollen tube of kiwi. In addition, Sterol 24-C methyltransferase 2-1 (Achn020241), SAM dependent carboxyl methyltransferase (Achn135281, Achn135291, Achn313791 and Achn313891) and O-methyltransferase (Achn135291, Achn104161, Achn371861 and Achn267681) were identified. Achn135291, Achn135281, Achn313791 and Achn313891 encode SAM dependent carboxyl methyltransferase enzymes that act on a variety of substrates including salycylic acid, jasmonic acid, and 7-methylxanthine. Methylation of jasmonate to methyljasmonate in plants acts as an important cellular regulator that mediates various processes of development in flowers [84]. Mutants associated with jasmonate synthesis or jasmonate signaling in Arabidopsis have male sterility, typically due to delayed development. The same genes that promote male fertility in Arabidopsis promote female fertility in tomatoes [85].

\subsection{Hormone-Related Genes Differentially Expressed in Male and Female Flowers}

Floral development is strongly affected by hormonal regulation [86]. Ethylene, which is the primary hormonal regulator of sexual expression and inhibits the development of stamen [87] in the Cucurbitaceae family and tobacco, is associated with the development of ovules, a factor that includes the ETR and ERF genes [88]. Studies have revealed that ERF genes function in various aspects of the growth, development, and physiology of plants, such as meristem activity and floral organ abscission [89-91]. In the DEG library, several genes were found under the ERF annotation (Achn359661, Achn334501, Achn224541, Achn219261, Achn033321) and ETR (Achn067861), with a higher number of transcripts in $\mathrm{G} \times \mathrm{T}$. In other studies, as Citrillus spp. family (water melon), ethylene has been shown to promote male flower development [92]. In addition, Salman-Minkov et al. [92] reported that the expression of CitACS3 in floral shoots and in open male flowers could be involved in the development of anthers under the regulation of ethylene [93]; within the context studied, the increase in ERF and ETR transcripts in male flowers could modulate CitACS3 for anther development.

Auxin is closely linked to the initiation of floral organ primordia and the alteration of auxin biosynthesis [94]. SMALL AUXIN UP RNA (SAUR) is a group of small proteins induced by auxins, capable of binding to $C a M$ [43] and altering the development of the apical hook [95]. SAUR68 has been reported to promote auxin-stimulated organ elongation such as hypocotyls, stamen filaments and petals, and SAUR63 promotes hypocotyl formation and stamen filament elongation. From the PPI analysis we report the presence of SAUR50 (Figure 4), a participant in cell lengthening [71].

Gibberellic acid insensitive (GAI; Achn239261) is a transcriptional regulator that acts as a repressor of the signaling pathway of GIBBERELLIN (GA), participates in large multiprotein complexes that repress the transcription of $G A$-inducible genes $[96,97]$ and its activity is regulated by auxin and ethylene [98-100]. Within this context, it has been reported that SLY1 regulates GA-Induced GAI Degradation [101]. In Figure 4 we can see that GAI interacts with other TFs such as $C O$ and $I A A 14$, and other protein families such as $J A Z 1$ and GID1B. The $M Y B$ family of genes participates in several signaling pathways. In this case, 
we could detect $24 M Y B$ transcripts, highlighting MYB61 (Achn189931) TF SARE involved in the synthesis [102], signaling, and degradation of gibberellins. Within the RNA-seq database described in this study, the $M Y B$ family presents SDRs between male and female flowers (Table S1). The determination of sex in plants is a complex process, where the interaction of TFs plays a determinant role in the processes that regulate reproduction and growth. There is a wide range of programs dedicated to preserving and integrating data on functional and transcriptomic studies, through sequencing, decoding, and mapping; these programs and are useful for unravelling the interaction between genes.

Akagi et al. [6] focused on the identification of the female sterility of Actinidia rufa $\times$ Actinidia chinensis, analyzed flower buds and young carpels of male and female plants, identifying a specific type $C$ cytokinin response regulator in the development of male flowers. This gene, called Shy Girl $(S y G l)$, is specifically expressed on the surface of the rudimentary carpel. The Shy Girl (SyGl) gene expression in mutant Nicotiana or Arabidopsis plants suppresses carpel development, resulting in female sterility. Due to the importance of this finding, the SyGi gene (Achn384741) was searched within the transcriptome; however, the FPKM values, in $\mathrm{G} \times \mathrm{T}$ and $\mathrm{H}$, were zero. This discrepancy with results reported by Agaki et al. [6], may be caused by the different floral stage. However, when we searched in the transcriptome in more depth, we identified genes such as Achn131111 and Achn112341 or Achn206301 up-regulated by male flowers, these being genes involved in the cytokinin pathway such as SyGi gene; however, the expression of these genes was very low (Table S1). Concretely, Achn112341 that encodes the cCytokinin riboside 5'-monophosphate phosphoribohydrolase has an activating function of cytokinins directly and controls the shoot of meristematic activity in Arabidopsis [103,104]. Moreover, in recent studies, [7] identified a new Y-encoded sex-determinant named Friendly Boy $(F r B y)$, which acts for the maintenance of male functions independently of SyGI. Therefore, FrBy is not expressed by female flowers as 'Hayward' while SyGI discriminates between male individuals (deletion presence) and hermaphrodite or female cultivars (deletion absence) as 'Hayward'.

\section{Conclusions}

The results obtained in this research provide valuable information suggesting new evidence on the genes and the mechanisms involved in the sex differentiation of kiwifruit plants. The RNA-seq of $A$. deliciosa flowers has allowed us to identify thousands of genes, of which 6413 DEGs are associated with the transduction of hormonal signals, development of floral and gametophytic organs, biological and metabolic processes, presuming these to be important in the floral determination and sexual differentiation. Our analyses point $A P 2$ and $A G$ genes as playing an essential role in the specification of floral identity and the determination of the floral meristem, respectively. Moreover, AS1 genes could be acting in a positive sense on the flowering linked to FT promoter and CO genes, which could be limiting the flowering time as happens in plant models as Arabidopsis. At hormonal level, genes from the $M Y B$ family seem to be related to gibberellic acid, jasmonate or auxin which are involved in the flowering processes showing MYB genes' differential expression between male and female flowers. Additionally, in the current work, several genes encoding methyltransferase enzymes were identified, being four of them Putative S-adenosyl-L-methionine-dependent methyltransferases. Therefore, this result suggests a possible epigenetic mechanism controlling the growth and development the pollen tube of kiwi flowers. However, it would be necessary to perform additional studies on specific organs of the flower, such as gynoecium and androecium, to determine precisely the role of each gene within the metabolic interaction that exists. Currently, the research associated with the determination of gender in Actinidia is based on the genomic cataloguing of DEGs, specific to the male gender, evidencing a regulatory response to type $C$ cytokinins, as a potential sex-regulating gene [6]. 
Supplementary Materials: The following are available online at https: / / www.mdpi.com/article/ 10.3390/horticulturae8010038/s1: Table S1: DEGs and the exact fold changes of TF between male and female flowers (xls); Table S2: Gene Ontology_Bingo (xls); Table S3: Analysis of enrichment of pathways_Kegg (xls); Table S4: PPI of the DEGs between female and male flowers_String (xls); and Table S5: Primers used in the reactions of RT-qPCR (xls). Figure S1: Heatmap of gene expression (FPKM) of genes displayed in the protein-protein interaction network expressed in female $(\mathrm{H})$ and male $(G \times T)$ flowers using Heatmapper tool by Euclidean distance. The different colours correspond to the transformed value $\log 10$. Figure S2: Heatmap of gene expression (FPKM) of genes associated with methyltransferase enzymes expressed in female $(\mathrm{H})$ and male $(\mathrm{G} \times \mathrm{T})$ flowers using Heatmapper tool by Euclidean distance. The different colours correspond to the transformed value $\log 10$.

Author Contributions: P.Z. and J.A.S. conceived the conceptualization and the experiment design. P.Z., M.G. and C.S.-A. performed the experiments and data analysis. P.Z., I.P., M.I.G. and J.A.S. developed the writing and original draft. C.J. and R.I. provided funding acquisition, project administration and resources. J.A.S. and R.I. carried out the visualization and review editing. All authors have read and agreed to the published version of the manuscript.

Funding: This research was funded by FONDEF (Chile), grant number $\mathrm{N}^{\circ}$ D09i-1136.

Institutional Review Board Statement: Not applicable.

Informed Consent Statement: Not applicable.

Data Availability Statement: All the raw reads in the FastQ format are available in the NCBI Short Read Archive (SRA) database under the bioproject numbers PRJNA750600 and PRJNA564374 for male flowers $(\mathrm{G} \times \mathrm{T})$ and female flowers $(\mathrm{H})$ respectively.

Acknowledgments: The authors would like to thank FONDEF $\mathrm{N}^{\circ}$ D09i-1136 and FONDECYT $\mathrm{N}^{\circ}$ 3160080 (Chile) research projects as well as Ministry of Science and Innovation (Spain) through the project “Juan de la Cierva Incorporación" N IJC2018-0366-I. Makarena Gonzalez thanks CONICYT for providing support through a PhD scholarship $\mathrm{N}^{\circ} 21202546$.

Conflicts of Interest: The authors declare no conflict of interest.

\section{References}

1. Zhang, Q.; Liu, C.; Liu, Y.; VanBuren, R.; Yao, X.; Zhong, C.; Huang, H. High-density interspecific genetic maps of kiwifruit and the identification of sex-specific markers. DNA Res. 2015, 22, 367-375. [CrossRef]

2. López-Sobaler, A.M.; Vizuete, A.A.; Anta, R.M.O. Beneficios nutricionales y sanitarios asociados al consumo de kiwi. Nutr. Hosp. 2016, 33, 21-25. [CrossRef] [PubMed]

3. Salinero, C.; Martino, J. Actinidia deliciosa (A. Chevalier, C.V. Liang et al., A. R. Ferguson) Kiwi. Edt. Excma. Diput Prov. Pontevedra 1997, 1, 1-3.

4. Liu, Z.; Larsson, S. The Relationship between a Flower Gall Midge Pseudas-Phondylia SP. (Diptera: Cecidomyiidae) and its Host Plant Actinidia Valvata. Insect Sci. 1996, 3, 271-282. [CrossRef]

5. Testolin, R.; Messina, R.; Lain, O.; Cipriani, G. A natural sex mutant in kiwifruit (Actinidia deliciosa). N. Z. J. Crop. Hortic. Sci. 2004, 32, 179-183. [CrossRef]

6. Akagi, T.; Henry, I.M.; Ohtani, H.; Morimoto, T.; Beppu, K.; Kataoka, I.; Tao, R. A Y-Encoded Suppressor of Feminization Arose via Lineage-Specific Duplication of a Cytokinin Response Regulator in Kiwifruit. Plant Cell 2018, 30, 780-795. [CrossRef]

7. Akagi, T.; Pilkington, S.M.; Varkonyi-Gasic, E.; Henry, I.M.; Sugano, S.S.; Sonoda, M.; Firl, A.; Mcneilage, M.A.; Douglas, M.J.; Wang, T.; et al. Two Y-chromosome-encoded genes determine sex in kiwifruit. Nat. Plants 2019, 5, 801-809. [CrossRef]

8. Harkess, A.; Zhou, J.; Xu, C.; Bowers, J.E.; Van Der Hulst, R.; Ayyampalayam, S.; Mercati, F.; Riccardi, P.; McKain, M.R.; Kakrana, A.; et al. The asparagus genome sheds light on the origin and evolution of a young Y chromosome. Nat. Commun. 2017, 8, 1279. [CrossRef]

9. Martin, A.; Troadec, C.; Boualem, A.; Rajab, M.; Fernandez, R.; Morin, H.; Pitrat, M.; Dogimont, C.; Bendahmane, A. A transposon-induced epigenetic change leads to sex determination in melon. Nat. Cell Biol. 2009, 461, 1135-1138. [CrossRef]

10. Sebastian, P.; Schaefer, H.; Telford, I.R.H.; Renner, S.S. Cucumber (Cucumis sativus) and melon (C. melo) have numerous wild relatives in Asia and Australia, and the sister species of melon is from Australia. Proc. Natl. Acad. Sci. USA 2010, 107, 14269-14273. [CrossRef] [PubMed]

11. Ming, R.; Bendahmane, A.; Renner, S.S. Sex Chromosomes in Land Plants. Annu. Rev. Plant Biol. 2011, 62, 485-514. [CrossRef] [PubMed]

12. Garcia, C.V.; Quek, S.-Y.; Stevenson, R.J.; Winz, R.A. Characterisation of bound volatile compounds of a low flavour kiwifruit species: Actinidia eriantha. Food Chem. 2012, 134, 655-661. [CrossRef]

13. Garcia, C.V.; Stevenson, R.J.; Atkinson, R.G.; Winz, R.A.; Quek, S.-Y. Changes in the bound aroma profiles of 'Hayward' and 'Hort16A' kiwifruit (Actinidia spp.) during ripening and GC-olfactometry analysis. Food Chem. 2013, 137, 45-54. [CrossRef] 
14. Barrett, D.M.; Beaulieu, J.; Shewfelt, R. Color, Flavor, Texture, and Nutritional Quality of Fresh-Cut Fruits and Vegetables: Desirable Levels, Instrumental and Sensory Measurement, and the Effects of Processing. Crit. Rev. Food Sci. Nutr. 2010, 50, 369-389. [CrossRef] [PubMed]

15. Jiang, Z.-Y.; Zhong, Y.; Zheng, J.; Ali, M.; Liu, G.-D.; Zheng, X.-L. L-ascorbic acid metabolism in an ascorbate-rich kiwifruit (Actinidia. Eriantha Benth.) cv. 'White' during postharvest. Plant Physiol. Biochem. 2018, 124, 20-28. [CrossRef] [PubMed]

16. Salazar, J.; Jorquera, C.; Campos-Vargas, R.; Jorgensen, C.; Zapata, P.; Infante, R. Effect of the application timing of 1-MCP on postharvest traits and sensory quality of a yellow-fleshed kiwifruit. Sci. Hortic. 2019, 244, 82-87. [CrossRef]

17. Atak, A.; Aydın, B.; Kahraman, K.A. Sex determination of kiwifruit seedlings with molecular markers. Acta Hortic. 2014, 197-203. [CrossRef]

18. Fraser, L.G.; Tsang, G.K.; Datson, P.M.; De Silva, H.N.; Harvey, C.F.; Gill, G.P.; Crowhurst, R.N.; Mcneilage, M.A. A gene-rich linkage map in the dioecious species Actinidia chinensis (kiwifruit) reveals putative X/Y sex-determining chromosomes. BMC Genom. 2009, 10, 102. [CrossRef]

19. Scaglione, D.; Fornasiero, A.; Pinto, C.; Cattonaro, F.; Spadotto, A.; Infante, R.; Meneses, C.; Messina, R.; Lain, O.; Cipriani, G.; et al. A RAD-based linkage map of kiwifruit (Actinidia chinensis Pl.) as a tool to improve the genome assembly and to scan the genomic region of the gender determinant for the marker-assisted breeding. Tree Genet. Genomes 2015, 11, 115. [CrossRef]

20. Harvey, C.F.; Gill, G.P.; Fraser, L.G.; Mcneilage, M.A. Sex determination in Actinidia. 1. Sex-linked markers and progeny sex ratio in diploid A. chinensis. Sex. Plant Reprod. 1997, 10, 149-154. [CrossRef]

21. Jiménez-Durán, K.; Cruz-García, F. Incompatibilidad sexual, un mecanismo genético que evita la autofecundación y con-tribuye a la diversidad vegetal. Rev. Fitotec. Mex. 2011, 34, 1-9.

22. Li, X.; Qin, H.; Wang, Z.; Zhang, Q.; Liu, Y.; Xu, P.; Zhao, Y.; Fan, S.; Yang, Y.; Ai, J. Differentially expressed genes in male and female flower buds of hardy kiwifruit (Actinidia Arguta (Sieb. et ZUCC.) Planch. Ex MIQ.). Bangladesh J. Bot. $2015,44,909-915$.

23. Tang, P.; Zhang, Q.; Yao, X. Comparative transcript profiling explores differentially expressed genes associated with sexual phenotype in kiwifruit. PLoS ONE 2017, 12, e0180542. [CrossRef]

24. Zuccherelli, G.; Zuccherelli, G. La actinidia (KIWI), 2nd ed.; Ediciones Mundi-Prensa: Madrid, Spain, $1990 ;$ ISBN 8471141167.

25. Salinero, M.; Vela, P.; Sainz, M. Phenological growth stages of kiwifruit (Actinidia deliciosa 'Hayward'). Sci. Hortic. 2009, 121, 27-31. [CrossRef]

26. Caporali, E.; Testolin, R.; Pierce, S.; Spada, A. Sex change in kiwifruit (Actinidia chinensis Planch.): A developmental framework for the bisexual to unisexual floral transition. Plant Reprod. 2019, 32, 323-330. [CrossRef] [PubMed]

27. Langmead, B.; Salzberg, S.L. Fast gapped-read alignment with Bowtie 2. Nat. Methods 2012, 9, 357-359. [CrossRef]

28. Li, H.; Handsaker, B.; Wysoker, A.; Fennell, T.; Ruan, J.; Homer, N.; Marth, G.; Abecasis, G.; Durbin, R.; 1000 Genome Project Data Processing Subgroup. The Sequence Alignment/Map format and SAMtools. Bioinformatics 2009, 25, 2078-2079. [CrossRef] [PubMed]

29. Trapnell, C.; Williams, B.A.; Pertea, G.; Mortazavi, A.; Kwan, G.; Van Baren, M.J.; Salzberg, S.L.; Wold, B.J.; Pachter, L. Transcript assembly and quantification by RNA-Seq reveals unannotated transcripts and isoform switching during cell differentiation. Nat. Biotechnol. 2010, 28, 511-515. [CrossRef] [PubMed]

30. Love, M.I.; Huber, W.; Anders, S. Moderated estimation of fold change and dispersion for RNA-seq data with DESeq2. Genome Biol. 2014, 15, 550. [CrossRef]

31. Mortazavi, A.; Williams, B.A.; McCue, K.; Schaeffer, L.; Wold, B. Mapping and quantifying mammalian transcriptomes by RNA-Seq. Nat. Methods 2008, 5, 621-628. [CrossRef]

32. Maere, S.; Heymans, K.; Kuiper, M. BiNGO: A Cytoscape plugin to assess overrepresentation of Gene Ontology categories in Biological Networks. Bioinformatics 2005, 21, 3448-3449. [CrossRef]

33. Otasek, D.; Morris, J.H.; Bouças, J.; Pico, A.R.; Demchak, B. Cytoscape Automation: Empowering workflow-based network analysis. Genome Biol. 2019, 20, 185. [CrossRef] [PubMed]

34. Bindea, G.; Galon, J.; Mlecnik, B. CluePedia Cytoscape plugin: Pathway insights using integrated experimental and in silico data. Bioinformatics 2013, 29, 661-663. [CrossRef]

35. Bindea, G.; Mlecnik, B.; Hackl, H.; Charoentong, P.; Tosolini, M.; Kirilovsky, A.; Fridman, W.-H.; Pagès, F.; Trajanoski, Z.; Galon, J. ClueGO: A Cytoscape plug-in to decipher functionally grouped gene ontology and pathway annotation networks. Bioinformatics 2009, 25, 1091-1093. [CrossRef] [PubMed]

36. Shannon, P.; Markiel, A.; Ozier, O.; Baliga, N.S.; Wang, J.T.; Ramage, D.; Amin, N.; Schwikowski, B.; Ideker, T. Cytoscape: A Software Environment for Integrated Models of Biomolecular Interaction Networks. Genome Res. 2003, 13, 2498-2504. [CrossRef]

37. Reimand, J.; Isserlin, R.; Voisin, V.; Kucera, M.; Tannus-Lopes, C.; Rostamianfar, A.; Wadi, L.; Meyer, M.; Wong, J.; Xu, C.; et al Pathway enrichment analysis and visualization of omics data using g:Profiler, GSEA, Cytoscape and EnrichmentMap. Nat. Protoc. 2019, 14, 482-517. [CrossRef] [PubMed]

38. Kanehisa, M.; Furumichi, M.; Tanabe, M.; Sato, Y.; Morishima, K. KEGG: New perspectives on genomes, pathways, diseases and drugs. Nucleic Acids Res. 2017, 45, D353-D361. [CrossRef] [PubMed]

39. Kanehisa, M.; Sato, Y.; Kawashima, M.; Furumichi, M.; Tanabe, M. KEGG as a reference resource for gene and protein annotation. Nucleic Acids Res. 2016, 44, D457-D462. [CrossRef] 
40. Szklarczyk, D.; Morris, J.H.; Cook, H.; Kuhn, M.; Wyder, S.; Simonovic, M.; Santos, A.; Doncheva, N.T.; Roth, A.; Bork, P.; et al. The STRING database in 2017: Quality-controlled protein-protein association networks, made broadly accessible. Nucleic Acids Res. 2017, 45, D362-D368. [CrossRef] [PubMed]

41. Kim, H.B.; Jun, S.S.; Choe, S.; Cho, J.Y.; Choi, S.B.; Kim, S.C. Identification of differentially expressed genes from male and female flowers of kiwifruit. Afr. J. Biotechnol. 2010, 9, 6684-6694.

42. Varkonyi-Gasic, E.; Lough, R.H.; Moss, S.; Wu, R.; Hellens, R. Kiwifruit floral gene APETALA2 is alternatively spliced and accumulates in aberrant indeterminate flowers in the absence of miR172. Plant Mol. Biol. 2012, 78, 417-429. [CrossRef] [PubMed]

43. Li, Z.-G.; Chen, H.-W.; Li, Q.; Tao, J.-J.; Bian, X.-H.; Ma, B.; Zhang, W.-K.; Chen, S.-Y.; Zhang, J.-S. Three SAUR proteins SAUR76, SAUR77 and SAUR78 promote plant growth in Arabidopsis. Sci. Rep. 2015, 5, 12477. [CrossRef]

44. Untergasser, A.; Cutcutache, I.; Koressaar, T.; Ye, J.; Faircloth, B.C.; Remm, M.; Rozen, S.G. Primer3-New capabilities and interfaces. Nucleic Acids Res. 2012, 40, e115. [CrossRef] [PubMed]

45. Zhou, Z.; Cong, P.; Tian, Y.; Zhu, Y. Using RNA-seq data to select reference genes for normalizing gene expression in apple roots. PLoS ONE 2017, 12, e0185288. [CrossRef]

46. Satyanarayana, P.; Guzdar, P.N.; Huba, J.D.; Ossakow, S.L. Rayleigh-Taylor instability in the presence of a stratified shear layer. J. Geophys. Res. Space Phys. 1984, 89, 2945. [CrossRef]

47. Tao, Q.; Niu, H.; Wang, Z.; Zhang, W.; Wang, H.; Wang, S.; Zhang, X.; Li, Z. Ethylene responsive factor ERF110 mediates ethylene-regulated transcription of a sex determination-related orthologous gene in two Cucumis species. J. Exp. Bot. 2018, 69, 2953-2965. [CrossRef] [PubMed]

48. Krizek, B.A.; Fletcher, J.C. Molecular mechanisms of flower development: An armchair guide. Nat. Rev. Genet. 2005, 6, 688-698. [CrossRef] [PubMed]

49. Krizek, A.B. Arabidopsis: Flower Development and Patterning. In Encyclopedia of Life Sciences (ELS); John Wiley \& Sons, Ltd.: Chichester, UK, 2020. [CrossRef]

50. Sharma, P.; Singh, R.; Sehrawat, N. A critical review on: Significance of floral homeotic APETALA2 gene in plant system. J. Appl. Pharm. Sci. 2020, 10, 124-130. [CrossRef]

51. Wollmann, H.; Mica, E.; Todesco, M.; Long, J.A.; Weigel, D. On reconciling the interactions between APETALA2, miR172 and AGAMOUS with the ABC model of flower development. Development 2010, 137, 3633-3642. [CrossRef]

52. Maes, T.; Van De Steene, N.; Zethof, J.; Karimi, M.; D’Hauw, M.; Mares, G.; Van Montagu, M.; Gerats, T. Petunia Ap2-like Genes and Their Role in Flower and Seed Development. Plant Cell 2001, 13, 229-244. [CrossRef]

53. Byzova, M.V.; Franken, J.; Aarts, M.G.; De Almeida-Engler, J.; Engler, G.; Mariani, C.; Campagne, M.M.V.L.; Angenent, G.C. Arabidopsis Sterile Apetala, a multifunctional gene regulating inflorescence, flower, and ovule development. Genes Dev. 1999, 13, 1002-1014. [CrossRef]

54. Pan, I.L.; McQuinn, R.; Giovannoni, J.J.; Irish, V.F. Functional diversification of AGAMOUS lineage genes in regulating tomato flower and fruit development. J. Exp. Bot. 2010, 61, 1795-1806. [CrossRef]

55. Huang, Z.; Shi, T.; Zheng, B.; Yumul, R.E.; Liu, X.; You, C.; Gao, Z.; Xiao, L.; Chen, X. APETALA 2 antagonizes the transcriptional activity of AGAMOUS in regulating floral stem cells in Arabidopsis thaliana. New Phytol. 2017, 215, 1197-1209. [CrossRef]

56. Ori, N.; Eshed, Y.; Chuck, G.; Bowman, J.; Hake, S. Mechanisms that control knox gene expression in the Arabidopsis shoot. Development 2000, 127, 5523-5532. [CrossRef]

57. Song, Y.H.; Lee, I.; Lee, S.Y.; Imaizumi, T.; Hong, J.C. Constans and Asymmetric Leaves 1 complex is involved in the induction of Flowering Locus $\mathrm{T}$ in photoperiodic flowering in Arabidopsis. Plant J. 2012, 69, 332-342. [CrossRef] [PubMed]

58. Shim, J.S.; Kubota, A.; Imaizumi, T. Circadian Clock and Photoperiodic Flowering in Arabidopsis: Constans is a Hub for Signal Integration. Plant Physiol. 2017, 173, 5-15. [CrossRef] [PubMed]

59. Shen, Y.; Xiang, Y.; Xu, E.; Ge, X.; Li, Z. Major Co-localized QTL for Plant Height, Branch Initiation Height, Stem Diameter, and Flowering Time in an Alien Introgression Derived Brassica napus DH Population. Front. Plant Sci. 2018, 9. [CrossRef]

60. Tiwari, S.B.; Shen, Y.; Chang, H.; Hou, Y.; Harris, A.; Ma, S.F.; McPartland, M.; Hymus, G.J.; Adam, L.; Marion, C.; et al. The flowering time regulator CONSTANS is recruited to the FLOWERING LOCUS T promoter via a unique cis-element. New Phytol. 2010, 187, 57-66. [CrossRef] [PubMed]

61. You, Y.; Sawikowska, A.; Neumann, M.; Posé, D.; Capovilla, G.; Langenecker, T.; Neher, R.A.; Krajewski, P.; Schmid, M. Temporal dynamics of gene expression and histone marks at the Arabidopsis shoot meristem during flowering. Nat. Commun. 2017, 8, 15120. [CrossRef] [PubMed]

62. Jue, D.; Sang, X.; Liu, L.; Shu, B.; Wang, Y.; Liu, C.; Xie, J.; Shi, S. Identification of WRKY Gene Family from Dimocarpus longan and Its Expression Analysis during Flower Induction and Abiotic Stress Responses. Int. J. Mol. Sci. 2018, 19, 2169. [CrossRef] [PubMed]

63. Chen, F.; Hu, Y.; Vannozzi, A.; Wu, K.; Cai, H.; Qin, Y.; Mullis, A.; Lin, Z.; Zhang, L. The WRKY Transcription Factor Family in Model Plants and Crops. Crit. Rev. Plant Sci. 2017, 36, 311-335. [CrossRef]

64. Amini, S.; Rosli, K.; Abu-Bakar, M.-F.; Alias, H.; Mat-Isa, M.-N.; Juhari, M.-A.-A.; Haji-Adam, J.; Goh, H.-H.; Wan, K.-L. Transcriptome landscape of Rafflesia cantleyi floral buds reveals insights into the roles of transcription factors and phytohormones in flower development. PLoS ONE 2019, 14, e0226338. [CrossRef]

65. Huang, R.; Liu, D.; Ma, J.; Li, M.; Sui, S. CpWRKY71, a WRKY Transcription Factor Gene of Wintersweet (Chimonanthus praecox), Promotes Flowering and Leaf Senescence in Arabidopsis. Int. J. Mol. Sci. 2019, 20, 5325. [CrossRef] [PubMed] 
66. Guan, Y.; Meng, X.; Khanna, R.; Lamontagne, E.; Liu, Y.; Zhang, S. Phosphorylation of a WRKY Transcription Factor by MAPKs Is Required for Pollen Development and Function in Arabidopsis. PLoS Genet. 2014, 10, e1004384. [CrossRef] [PubMed]

67. Zheng, Z.; Abu Qamar, S.; Chen, Z.; Mengiste, T. Arabidopsis WRKY33 transcription factor is required for resistance to necrotrophic fungal pathogens. Plant J. 2006, 48, 592-605. [CrossRef]

68. Gregis, V.; Sessa, A.; Colombo, L.; Kater, M.M. AGL24, Short Vegetative Phase, and Apetala1redundantly Control Agamous during Early Stages of Flower Development in Arabidopsis. Plant Cell 2006, 18, 1373-1382. [CrossRef]

69. Gregis, V.; Sessa, A.; Dorca-Fornell, C.; Kater, M.M. The Arabidopsis floral meristem identity genes AP1, AGL24 and SVP directly repress class B and C floral homeotic genes. Plant J. 2009, 60, 626-637. [CrossRef]

70. Dorca-Fornell, C.; Gregis, V.; Grandi, V.; Coupland, G.; Colombo, L.; Kater, M.M. The Arabidopsis SOC1-like genes AGL42, AGL71 and AGL72 promote flowering in the shoot apical and axillary meristems. Plant J. 2011, 67, 1006-1017. [CrossRef]

71. Van Mourik, H.; Van Dijk, A.D.J.; Stortenbeker, N.; Angenent, G.C.; Bemer, M. Divergent regulation of Arabidopsis SAUR genes: A focus on the SAUR10-clade. BMC Plant Biol. 2017, 17, 245. [CrossRef]

72. Becker, A. The major clades of MADS-box genes and their role in the development and evolution of flowering plants. Mol. Phylogenet. Evol. 2003, 29, 464-489. [CrossRef]

73. Adamczyk, B.J.; Lehti-Shiu, M.D.; Fernandez, D.E. The MADS domain factors AGL15 and AGL18 act redundantly as repressors of the floral transition in Arabidopsis. Plant J. 2007, 50, 1007-1019. [CrossRef]

74. Nakaminami, K.; Hill, K.; Perry, S.E.; Sentoku, N.; Long, J.A.; Karlson, D.T. Arabidopsis cold shock domain proteins: Relationships to floral and silique development. J. Exp. Bot. 2009, 60, 1047-1062. [CrossRef] [PubMed]

75. Chen, M.-K.; Hsu, W.-H.; Lee, P.-F.; Thiruvengadam, M.; Chen, H.-I.; Yang, C.-H. The MADS box gene, Forever Young Flower, acts as a repressor controlling floral organ senescence and abscission in Arabidopsis. Plant J. 2011, 68, 168-185. [CrossRef] [PubMed]

76. Cheng, Y.-H.; Peng, X.-Y.; Yu, Y.-C.; Sun, Z.-Y.; Han, L. The Effects of DNA Methylation Inhibition on Flower Development in the Dioecious Plant Salix Viminalis. Forests 2019, 10, 173. [CrossRef]

77. Yang, H.; Chang, F.; You, C.; Cui, J.; Zhu, G.; Wang, L.; Zheng, Y.; Qi, J.; Ma, H. Whole-genome DNA methylation patterns and complex associations with gene structure and expression during flower development in Arabidopsis. Plant J. 2014, 81, 268-281. [CrossRef]

78. Soppe, W.J.; Jacobsen, E.S.; Alonso-Blanco, C.; Jackson, J.P.; Kakutani, T.; Koornneef, M.; Peeters, A.J. The Late Flowering Phenotype of fwa Mutants is Caused by Gain-of-Function Epigenetic Alleles of a Homeodomain Gene. Mol. Cell 2000, 6, 791-802. [CrossRef]

79. Law, J.A.; Jacobsen, S.E. Establishing, maintaining and modifying DNA methylation patterns in plants and animals. Nat. Rev. Genet. 2010, 11, 204-220. [CrossRef]

80. Zhang, Y.; He, X.; Zhao, H.; Xu, W.; Deng, H.; Wang, H.; Wang, S.; Su, D.; Zheng, Z.; Yang, B.; et al. Genome-Wide Identification of DNA Methylases and Demethylases in Kiwifruit (Actinidia chinensis). Front. Plant Sci. 2020, 11, 1380. [CrossRef]

81. Kim, S.-C.; Uhm, Y.K.; Ko, S.; Oh, C.J.; Kwack, Y.-B.; Kim, H.L.; Lee, Y.; An, C.S.; Park, P.B.; Kim, H.B. KiwiPME1 encoding pectin methylesterase is specifically expressed in the pollen of a dioecious plant species, kiwifruit (Actinidia chinensis). Hortic. Environ. Biotechnol. 2015, 56, 402-410. [CrossRef]

82. Wormit, A.; Usadel, B. The Multifaceted Role of Pectin Methylesterase Inhibitors (PMEIs). Int. J. Mol. Sci. 2018, 19, 2878. [CrossRef]

83. Zhang, G.Y.; Feng, J.; Wu, J.; Wang, X.W. BoPMEI1, a pollen-specific pectin methylesterase inhibitor, has an essential role in pollen tube growth. Planta 2010, 231, 1323-1334. [CrossRef] [PubMed]

84. Seo, H.S.; Song, J.T.; Cheong, J.-J.; Lee, Y.-H.; Lee, Y.W.; Hwang, I.; Lee, J.S.; Choi, Y.D. Jasmonic acid carboxyl methyltransferase: A key enzyme for jasmonate-regulated plant responses. Proc. Natl. Acad. Sci. USA 2001, 98, 4788-4793. [CrossRef] [PubMed]

85. Wasternack, C. Jasmonates: An Update on Biosynthesis, Signal Transduction and Action in Plant Stress Response, Growth and Development. Ann. Bot. 2007, 100, 681-697. [CrossRef] [PubMed]

86. Chandler, J.W. The Hormonal Regulation of Flower Development. J. Plant Growth Regul. 2011, 30, 242-254. [CrossRef]

87. Manzano, S.; Martínez, C.; García, J.M.; Megías, Z.; Jamilena, M. Involvement of ethylene in sex expression and female flower development in watermelon (Citrullus lanatus). Plant Physiol. Biochem. 2014, 85, 96-104. [CrossRef]

88. Sun, J.-J.; Li, F.; Li, X.; Liu, X.-C.; Rao, G.-Y.; Luo, J.-C.; Wang, D.-H.; Xu, Z.-H.; Bai, S.-N. Why is ethylene involved in selective promotion of female flower development in cucumber? Plant Signal. Behav. 2010, 5, 1052-1056. [CrossRef] [PubMed]

89. Chen, W.-H.; Li, P.-F.; Chen, M.-K.; Lee, Y.-I.; Yang, C.-H. Forever young Flower Negatively Regulates Ethylene Response DNABinding Factors by Activating an Ethylene-Responsive Factor to Control Arabidopsis Floral Organ Senescence and Abscission. Plant Physiol. 2015, 168, 1666-1683. [CrossRef]

90. Liu, J.; Li, J.; Wang, H.; Fu, Z.; Liu, J.; Yu, Y. Identification and expression analysis of ERF transcription factor genes in petunia during flower senescence and in response to hormone treatments. J. Exp. Bot. 2010, 62, 825-840. [CrossRef]

91. Nakano, T.; Fujisawa, M.; Shima, Y.; Ito, Y. The AP2/ERF transcription factor SlERF52 functions in flower pedicel abscission in tomato. J. Exp. Bot. 2014, 65, 3111-3119. [CrossRef]

92. Salman-Minkov, A.; Levi, A.; Wolf, S.; Trebitsh, T. ACC Synthase Genes are Polymorphic in Watermelon (Citrullus spp.) and Differentially Expressed in Flowers and in Response to Auxin and Gibberellin. Plant Cell Physiol. 2008, 49, 740-750. [CrossRef]

93. Lin, Z.; Zhong, S.; Grierson, D. Recent advances in ethylene research. J. Exp. Bot. 2009, 60, 3311-3336. [CrossRef] 
94. Li, W.; Zhou, Y.; Liu, X.; Yu, P.; Cohen, J.D.; Meyerowitz, E.M. LEAFY Controls Auxin Response Pathways in Floral Primordium Formation. Sci. Signal. 2013, 6, ra23. [CrossRef] [PubMed]

95. Park, J.-E.; Kim, Y.-S.; Yoon, H.-K.; Park, C.-M. Functional characterization of a small auxin-up RNA gene in apical hook development in Arabidopsis. Plant Sci. 2007, 172, 150-157. [CrossRef]

96. Fu, X.; Sudhakar, D.; Peng, J.; Richards, D.E.; Christou, P.; Harberd, N.P. Expression of Arabidopsis GAI in Transgenic Rice Represses Multiple Gibberellin Responses. Plant Cell 2001, 13, 1791-1802. [CrossRef] [PubMed]

97. Qu, J.; Kang, S.G.; Hah, C.; Jang, J.-C. Molecular and cellular characterization of GA-Stimulated Transcripts GASA4 and GASA6 in Arabidopsis thaliana. Plant Sci. 2016, 246, 1-10. [CrossRef]

98. Gomez, M.D.; Barro-Trastoy, D.; Escoms, E.; Saura-Sanchez, M.; Sánchez, I.; Briones-Moreno, A.; Vera-Sirera, F.; Carrera, E.; Ripoll, J.J.; Yanofsky, M.F.; et al. Gibberellins negatively modulate ovule number in plants. Development 2018, 145, 163865. [CrossRef]

99. Zentella, R.; Yamauchi, D.; Ho, T.-H.D. Molecular Dissection of the Gibberellin/Abscisic Acid Signaling Pathways by Transiently Expressed RNA Interference in Barley Aleurone Cells. Plant Cell 2002, 14, 2289-2301. [CrossRef]

100. Zhang, D.; Ren, L.; Yue, J.-H.; Wang, L.; Zhuo, L.-H.; Shen, X.-H. A comprehensive analysis of flowering transition in Agapanthus praecox ssp. orientalis (Leighton) Leighton by using transcriptomic and proteomic techniques. J. Proteom. 2013, 80, 1-25. [CrossRef]

101. Dill, A.; Thomas, S.G.; Hu, J.; Steber, C.M.; Sun, T.-P. The Arabidopsis F-Box Protein SLEEPY1 Targets Gibberellin Signaling Repressors for Gibberellin-Induced Degradation. Plant Cell 2004, 16, 1392-1405. [CrossRef]

102. Matías-Hernández, L.; Jiang, W.; Yang, K.; Tang, K.; Brodelius, P.E.; Pelaz, S. AaMYB1 and its orthologue AtMYB61 affect terpene metabolism and trichome development inArtemisia annua and Arabidopsis thaliana. Plant J. 2017, 90, 520-534. [CrossRef]

103. Kurakawa, T.; Ueda, N.; Maekawa, M.; Kobayashi, K.; Kojima, M.; Nagato, Y.; Sakakibara, H.; Kyozuka, J. Direct control of shoot meristem activity by a cytokinin-activating enzyme. Nature 2007, 445, 652-655. [CrossRef] [PubMed]

104. Kuroha, T.; Tokunaga, H.; Kojima, M.; Ueda, N.; Ishida, T.; Nagawa, S.; Fukuda, H.; Sugimoto, K.; Sakakibara, H. Functional Analyses of Lonely Guy Cytokinin-Activating Enzymes Reveal the Importance of the Direct Activation Pathway in Arabidopsis. Plant Cell 2009, 21, 3152-3169. [CrossRef] [PubMed] 